\title{
LCA in Environmental Management Systems—Results of Individual Interviews with Selected Enterprises from Poland and Sweden
}

\section{Katarzyna Joachimiak-Lechman}

Department of Industrial Products Ecology and Quality, Faculty of Commodity Science, Poznan University of Economics, Poznan, Poland.

Email: katarzyna.joachimiak@ue.poznan.pl

Received February $10^{\text {th }}, 2013$; revised March 12 ${ }^{\text {th }}, 2013$; accepted April $9^{\text {th }}, 2013$

Copyright (C) 2013 Katarzyna Joachimiak-Lechman. This is an open access article distributed under the Creative Commons Attribution License, which permits unrestricted use, distribution, and reproduction in any medium, provided the original work is properly cited.

\begin{abstract}
Life Cycle Assessment (LCA) is an analytical tool used for the environmental optimization of products and services within the entirety of its life cycle. ISO 14040 recommends use of the technique in numerous areas of environmental management such as in designing for the environment, eco-labelling, environmental communications and the assessment of the effects of environmental activities. Despite being theoretically feasible, certain applications of the ecological assessment of a life cycle such as the possibility of identification and evaluation of environmental aspects with the use of LCA are, in practice, still new to many environmental managers. With its strong points, the technique seems to be a valuable tool, especially in the context of apparent concepts of Product-Oriented Environmental Management Systems (POEMS). In order to verify the hypothesis, the author decided to verify the level of use of LCA in the area of identification and assessment of environmental aspects in selected organizations. Therefore, questionnaire interviews were conducted with representatives of selected Polish and Swedish enterprises who, at the time of the interview, had certified environmental management systems. The organizations were analyzed with respect to applied methods and techniques used for identification and assessment of environmental aspects as well as the degree of use of LCA both in this respect and in other areas of environmental management. This paper will present the results of this research and conclusions.
\end{abstract}

Keywords: Environmental Management System; Life Cycle Assessment; ISO 14001; Environmental Aspects; Identification; Assessment

\section{Introduction}

Deterioration of the natural environment necessitated ecological activities not only on the part of consumers, but also on the part of economic entities as well. The idea of permanent and sustainable development exerts a growing influence upon the formation of theories and practice in numerous fields of life, including the theory and practice of management [1]. This is reflected in even stronger determination of enterprises to develop their environmental activities. Tools that support such initiatives, include, amongst others, formalized environmental management systems oriented to management of environmental aspects that, in the light of ISO 14001, are defined as elements of activities of an organization, its products and services, that may interact with the envi- ronment [2]. Since the key element of the systems includes identification and assessment of environmental aspects, it is recommended that this process should be a starting point for the planning of ecological activities. Environmental aspects may be used not only during construction and maintenance of the environmental management system, but, significantly, in improvement of the system, as such aspects have an influence upon all activities realized as part of implementation, maintenance and improvement of the environmental management system [3].

\subsection{Life Cycle Thinking and Environmental Management Systems}

Life cycle management is significant from a practical 
point of view and, at the same time, it is a method for the introduction of a concept of life cycle thinking with its aim to manage the products, services and activities of an organization in such a manner as to ensure more and more sustainable production and consumption [4]. In order to meet the idea of sustainable development, concepts were propagated involving minimization of the negative effects of a product upon the environment in the entire life cycle of the product. Therefore, nowadays an approach to environmental management that is based upon life cycle is becoming more and more popular and this approach does not focus upon the very organization and its processes, but on all effects of manufactured goods on the environment [5]. This concept of the creation of an environmental management system perceived at the level of life cycle of products and services is referred to in literature as Product-Based Environmental Management System (PBEMS) [6] or Product-Oriented Environmental Management System (POEMS) [7,8]. Product-based environmental management systems often refer to Life Cycle Assessment (LCA) and, at the same time, propagate the application of the same in various aspects of product management. LCA uses normalized methodology presented in ISO 14000 series standards and is undoubtedly a tool for realization of fundamental assumptions of POEMS: this involves considering all of the environmental effects of a product and reduction of the effects within the entire life cycle, i.e. starting from the stage of design, through to production, maintenance and ending with final disposal.

LCA is an environmental management tool based upon physical values with its methodology representing three systems, namely technical, social and natural systems [9]. The LCA technique is characterized by considerable flexibility, which provides a whole range of possible fields of application ranging from sectoral analysis used on a macro scale, through to use in public policy to use at a level of a single organization [10]. There are a lot of fields of environmental management, for which LCA constitutes a potentially valuable tool for example, designing for the environment [6], eco-labeling and environmental communications [11], assessment of environmental activities and determination of environmental targets [12]. Thus, LCA results may constitute a prerequisite for making decisions related to a product and the modernization of existing undertaking as well as the creation of new environmentally-friendly investments [13].

\subsection{Identification and Assessment of Environmental Aspects-LCA as Compared to Conventional Methods and Techniques}

As it has already been emphasized, an effective process of identification and assessment of environmental aspects is a priority task during implementation, maintenance and improvement of the Environmental Management System. There are no standards that impose a method of realization on such activities, however, it is recommended that each organization should adopt an approach suitable to its scope, character and scale as well as to meet its demands as regards to details, complexity, time, costs and availability of reliable data [2]. Results of reviews of literature in this respect show a multitude of methods and techniques used for identification and assessment of environmental aspects ranging from typical qualitative approaches, through to semi-quantitative solutions, to quantitative methods. In practice, enterprises often use a combination of various methods that complement one another and, at the same time, ensure reliability of the obtained results.

Identification of environmental aspects may assume various forms such as, the following: brainstorming, process diagrams and analyses, interviews, inspections etc. [14] use of control charts, SIPOC diagrams, energy and material balance sheets [15]. Another solution used, amongst others, for the purposes of collection of requisite information relating to environmental aspects, is benchmarking and grid method [16]. On the other hand, traditional methods of assessment of environmental aspects include a score method, $\mathrm{ABC} / \mathrm{XYZ}$ method (Pareto analysis, 80/20 method) and FMEA analysis [15].

Each of the aforementioned qualitative and semiquantitative methods is characterized by its weak and strong points. The weakest points seem to include a general and excessively simplified method of determination of cause and effect character between an aspect and its effects upon the environment. Therefore, the typically quantitative LCA technique enables the calculation of effects on the environment on the basis of specified and scientifically proven models. In addition, consideration of all stages of life cycle in the analysis is needed constituting a valuable alternative to the commonly used conventional solutions.

As far as the applied approaches to assessment of environmental aspects are concerned, they may be divided into three general groups [17]: Risk Assessment methodology (RA based methods), Life Cycle Assessment methodology (LCA based methods) and non-environmental assessment criteria (criterion-based methods). Methods representing the first group mostly relate to abnormal and incidental aspects and serve to assess a given aspect at the level of frequency of its occurrence, scale, duration and harmful character. However, it is criticized that this harmful character of an aspect/influence is assessed without theoretical support, and, consequently, the assessment is too biased. Contrary to methods based on risk assessment, in the approach based on 
the environmental assessment of life cycle, harmful characters of influence of a given aspect on the environment is estimated with the use of specified scientific models. This methodology does not consider aspects occurring in emergency situations. The third group of methods relates to social and economic criteria of assessment of aspects such as legal requirements, interested parties or a public image, however, score calculation algorithms used in this approach are too simple, as they involve adding, multiplying or a linear combination [17]. Although ISO 14040 indicates directly to possible use of LCA in the field of identification and assessment of environmental aspects in Environmental Management Systems, it seems that this application is rarely found in an economic space and, in particular, in a Polish economic space. In some publications relating to this issue [10, 17-23] the LCA technique was shown to have theoretical potential and to be useful in methodology in this respect and to have restrictions resulting from its specific character which do not disqualify its application in the field of identification and assessment of environmental aspects. The presented results constitute a part of a greater project $[22,23]$, however, they have not been published so far and include results of individual interviews conducted with individual companies. Continuing the research related to use of LCA in Environmental Management Systems, they made an attempt to verify, whether and to what degree, LCA is, in practice, applied during the identification and assessment of environmental aspects. The next part of this paper presents the procedure and results of the research conducted.

\subsection{Interviews-Scopes of Research}

The fundamental aim of the research was determined as: verification, whether and to what degree, the LCA technique is used for identification and assessment of environmental aspects in environmental management systems and whether there are any differences in this respect between enterprises operating in Poland and Sweden. The spatial scope of the research was selected on purposes and in consideration to disproportions as regards experience of the aforementioned countries both in relation to environmental management systems and the very LCA. During the 1990s, LCA was analyzed in industry and business in four European countries, including Sweden $[24,25]$. They showed a considerable interest in Swedish entrepreneurs in LCA issues. In Poland, popularity surveys relating to LCA in its economic space so far have not been conducted and therefore there is no statistical data available in this respect. However, a review of literature makes it possible to conclude that analyses of LCA made in Poland are mainly used for research and scientific purposes [26]. Additionally, in choosing the spatial scope of this research, reports relating to the level of ecological awareness in the discussed societies were analyzed [27]. Divergences shown in the issue of ecological attitudes of Swedish and Polish consumers make it possible to assume that differences in awareness of the analyzed societies have an influence upon popularity of LCA not only in the analyzed area, but, generally, in environmental management.

In order to attain the research target, decided to conduct questionnaire interviews with representatives of Polish and Swedish enterprises that comply with the criterion involving the implementation of a certified Environmental Management System in accordance with requirements of the ISO 14001 or EMAS regulation. The research project constitutes a follow-up of a previously undertaken initiative to conduct questionnaire research with the use of CASI technique [22,23]. The selection of a traditional method such as a personal interview, was conditioned upon its strong points in comparison with computer-aided techniques such as, amongst others, direct contact between a surveyor and respondent and the certainty that the right person participates in the survey as well as possibility of explaining all ambiguities to the respondent.

A sample was determined with the use of available Polish and Swedish databases of enterprises cooperating with research centers that coordinate the described research. However, they ensured that the research institutions were not the same as institutions selected for questionnaire research with the use of CASI.

The first stage of the research involved telephone contact with environmental managers or other specialists in the environmental protection of enterprises in order to obtain an initial approval for the interview. Furthermore, they sent the interview scenario to the interested companies by e-mail. The interview was always conducted in the headquarters of an enterprise and at a date and time indicated by the respondent.

\subsection{The Interview Questionnaire}

The interview was conducted in accordance with the scenario previously approved by the respondent and included an introduction, contents and conclusion. The first major part of the interview included questions relating to an Environmental Management System in place in the company and the method of realization of an identification process and assessment of environmental aspects. The other part of the scenario differed depending on use of LCA in the discussed area. Respondents who declared use of the technique for identification and assessment of environmental aspects were asked questions relating to applied LCA methodology elements and demonstrated strong and weak points of the approach as well as other 
applications of the LCA technique. On the other hand, respondents applying traditional methods of identification and assessment of environmental aspects were asked questions with the purposes of verification of their awareness of LCA existence and any application of this tool in other areas. If an answer to the first question relating to any knowledge of LCA was negative, further questions planned for this part were abandoned.

\subsection{Characteristics of Organizations Participating in the Research}

A willingness to participate in the interviews was declared by 11 out of 25 enterprises, to which a request was sent relating to the possibility of the research. Six of them were organizations operating in Sweden and five of them in Poland. All enterprises employ more than 100 employees in total.

Each of the analyzed organizations had an implemented and certified Environmental Management System in compliance with requirements of ISO 14001. Additionally, one of the organizations participated in EcoManagement System and EMAS Audit. Considering the maturity of the aforementioned systems, it should be noted that, in the case of Sweden, they had been operating for more than 10 years (and up to 18 years in one case). In Polish organizations covered by research Environmental Management Systems had been operating for less than 10 years.

Swedish organizations covered by the research mostly represented industrial processing sectors and two of them represented service sectors relating to building as well as transport and communications. The four Polish organizations participating in the research conducted production activities and the fifth organization dealt with waste disposal services. As it was originally assumed, experts in environmental issues or experts in similar issues representing a given enterprise participated in the interviews.

\section{Research Results}

\subsection{Analysis of Part 1 of the Interview}

This part of the paper will present the results of the research conducted, namely the first part of the interview relating to tools used for identification and assessment of environmental aspects. In the process of identification of environmental aspects, most of the Swedish enterprises covered by the analysis applied a whole range of conventional methods, such as interviews and brainstorming ( $67 \%$ of enterprises $\left.{ }^{1}\right)$, inspections $(50 \%$ of enterprises) and control charts (33\% of enterprises). Two of the six

\footnotetext{
${ }^{1}$ Percentage of organizations providing a given answer to a specified question in relation to the number of organizations from a given country that participated in the research.
}

analyzed organizations (33\%) declared that apart from traditional methods (control charts, interviews) they used LCA as a technique for the identification of environmental aspects in Environmental Management Systems.

Most of the enterprises also assessed environmental aspects in a customary manner, however, contrary to the process of identification, this assessment is mainly realized with the use of one method. Appertaining to assessment of the environmental aspects the following approaches may be distinguished: FMEA (33\% of enterprises), score method (33\% of enterprises), qualitative and descriptive assessment (17\% of enterprises). Two analyzed organizations (33\%) that then confirmed the use of LCA during the identification of environmental aspects confirmed the use of LCA for the purposes of the assessment of environmental aspects. For one organization this was not the only assessment technique, as in the case of qualitative aspects, a descriptive assessment was additionally used.

Of all the Polish enterprises covered by the research, none confirmed the use of LCA during identification and assessment of environmental aspects. Similar to the Swedish entities, during the identification of aspects, interviews ( $80 \%$ of enterprises) and brainstorming (60\% of enterprises) were most often used. Three enterprises $(60 \%)$ were also supported by process diagrams and one $(20 \%)$ by control charts. All the Polish organizations participating in the research declared that they used only one method of assessment of environmental aspects, which was the score method. Collective results of the research are presented in Table $\mathbf{1}$.

Table 1. Methods and techniques used for the identification and assessment of environmental aspects.

\begin{tabular}{ccc}
\hline & Sweden & Poland \\
\hline 1) Methods and techniques used for the identification \\
of environmental aspects & \\
\hline Interviews & $67 \%$ & $80 \%$ \\
Brainstorming & $67 \%$ & $60 \%$ \\
Inspections & $50 \%$ & $0 \%$ \\
Process diagrams & $0 \%$ & $60 \%$ \\
Control charts & $33 \%$ & $20 \%$ \\
LCA & $33 \%$ & $0 \%$ \\
\hline 2) Methods and techniques used for the assessment \\
of environmental aspects & \\
\hline FMEA & $33 \%$ & $0 \%$ \\
Score method \\
$\begin{array}{c}\text { Qualitative and } \\
\text { descriptive assessment } \\
\text { LCA }\end{array}$ & $33 \%$ & $100 \%$ \\
\hline
\end{tabular}


As a criterion of assessment, each enterprise provided a scale of influence of an aspect as well as the legal requirements. Moreover, they most often signaled a harmful character of influence (60\% of enterprises), requirements of the interested parties (60\% of enterprises), intensity of influence ( $40 \%$ of enterprises) and frequency of occurrence of an aspect ( $40 \%$ of enterprises). Collective results of the research are presented Table 2.

\subsection{Analysis of Part 2A of the Interview}

The other part of the interview with its results presented below was designed for enterprises using the LCA technique for identification and assessment of environmental aspects and evaluation of environmental aspects and is related to elements of LCA methodology used for this purpose. Both organizations that declared using LCA in the analyzed area perform computer-aided analyses with the use of GaBi software. The first of the analyzed enterprises performs LCA on a regular basis depending on the need to update the register for environmental aspects, however, it did not always perform a complete LCA research for this purpose (a functional entity is determined and the process is divided into specific processes). On the other hand, LCA results are presented, as necessary, in the form of environmental profiles or eco-indicator values and, apart from legal requirements and requirements of interested parties, constitute the main criterion for assessment of environmental aspects.

The second of the analyzed organizations also declared using LCA on a regular basis in the area of identification and assessment of environmental aspects. However, in this case, apart from the functional unit and division into specific processes, methodological elements used for the identification of aspects also include cut-off criteria. Results are also presented in the form of environmental profiles or eco-indicator values.

Both the first and the other respondents particularly emphasized the usefulness of the LCA technique for identification and assessment of environmental aspects. Above all, they emphasized the quantitative character of the research, the reliability of results as well as the simplicity and promptness of the procedure (with the assumption of considerable experience and knowledge of the surveyor). The weak point of this approach included, above all, restrictions resulting from description parameters and lack of opportunities to consider qualitative aspects.

\subsection{Analysis of Part 2B of the Interview}

Each of the Swedish respondents, who confirmed the use of customary methods and techniques used for identification and assessment of environmental aspects in Envi-
Table 2. The most frequently used criteria for the assessment of environmental aspects.

\begin{tabular}{cc}
\hline Criterion of assessment & $\begin{array}{c}\text { Percentage of organizations } \\
\text { applying a given criterion }\end{array}$ \\
\hline Legal requirements & 100 \\
Scale of influence & 100 \\
Harmfulness of influence & 60 \\
Requirements of interested parties & 60 \\
Intensity of influence & 40 \\
Frequency of aspect occurrence & 40 \\
\hline
\end{tabular}

ronmental Managements Systems, was aware of the existence of the LCA technique and its possible applications. Two out of the four organizations that answered the questions in this part of the interview, declared that their technique was applied in other areas of environmental management. They stated that LCA results were used for environmental design and supported decision-making systems. One of the enterprises declared that it used LCA for the purposes of the modification of products offered in order to limit electrical energy consumption and carbon dioxide emission. The other of the enterprises ensured that it conducted a comprehensive LCA research (the entire life cycle of a product was analyzed) and its results were used for the formulation of key reasons for environmental effects. The research had a comparative character with its aim to compare a standard product to a modified one in order to make most favorable choices of solutions for the environment. Additionally, one of the enterprises participating in this part of the interview declared that LCA results constituted a prerequisite for decision-making relating to qualification of suppliers.

Each of the respondents answering questions in this part of the interview was aware of obvious strong points in the use of the LCA approach for identification and assessment of environmental aspects in Environmental Management Systems, however, due to a long period of analysis and the complexity of the procedure, they did not consider using this tool for a specific purpose in the future.

Most of the representatives of the Polish organizations $(80 \%)$ participating in the interviews showed their awareness of the existence of the LCA tool and its applications. Unfortunately, as it was shown, the analyzed enterprises did not use the LCA technique for the identification and assessment of environmental aspects nor for any other purposes. They often admitted that they had never considered conducting LCA research to any extent. They argued that such an analysis was expensive and time-consuming. LCA is not perceived by the analyzed Polish enterprises as an appropriate alternative to conventional methods and the traditional approach applied is 
deemed fully sufficient.

\section{Correlations}

Due to the fact that out of 11 enterprises participating in the research, there were two enterprises that declared using LCA in the analyzed area, it is impossible to determine correlations between a specific character of an enterprise and the degree of use of the LCA technique as a tool for environmental management. Analyzing the profile of two enterprises, that declared using LCA for the identification and assessment of environmental issues, it should be emphasized that the organizations have great experience in Environmental Management Systems and declare use of other tools based on the prospect of the entire life cycle such as LCC and SLCA as well as LCA in other areas of environmental management. Moreover, one of the enterprises confirmed the ecological character of its products by using such eco-labels as EU Ecolabel, Nordic Swan, Blue Angel and Energy Star. This means that the use of LCA in any area expresses a certain "ecological" maturity of an enterprise and advanced process of product management.

It should be noted that the LCA technique is characterized by versatility, which means that it may be used by any enterprise, regardless of its size, sector and social and economic conditions. LCA may be used by both service and production companies. However, it seems that it may prove particularly useful as a tool for the identification and assessment of environmental aspects in Environmental Management Systems for production enterprises that most frequently identify more quantitative aspects, prepare material and energy balance sheets and monitor technological processes. It is worth noting that both Swedish enterprises that declared using LCA in the analyzed area represent production sectors (production of chemicals and chemical products as well as the production of parts and accessories for mechanical vehicles). Obviously, this fact does not disqualify LCA as a possible tool to be used by service entities and it only proves that production enterprises find it easier to collect data suitable for LCA analyses [28].

\section{Conclusions}

In reference to the aim of this paper we should say that in the group of the analyzed Swedish enterprises, there were cases of use of the LCA technique for identification and assessment of environmental aspects. In the case of two Swedish enterprises (33\% of the sample) that agreed to participate in the interview, the use of LCA in the analyzed area was confirmed. Considering the assumed little percentage of companies with experience in the use of LCA in the area of environmental aspects in Environ- mental Management Systems, it may be stated that LCA enjoys a moderate popularity in this specific use. The analyzed Polish organizations did not indicate LCA as a tool for identification and assessment of environmental aspects and, what is more, the organizations did not declare using LCA in any area of management. This confirms the fact that Polish entrepreneurs still exclude LCA from their interests. Thus, one may conclude that differences existing between the analyzed countries with regarding ecological awareness of their societies, popularity of eco-labeling, Environmental Management Systems and within the LCA itself can be translated into popularity of the tool during identification and assessment of environmental aspects.

It should be clearly emphasized that the interviews were conducted on a small scale and, therefore, one should be cautious in attempting to come to far-fetched conclusions. However, considering that four out of the six analyzed Swedish enterprises confirmed the use of LCA in environmental management (in the analyzed area and during eco-designing), one may assume that the technique enjoys a relatively large interest in Sweden. However, in Poland the research into LCA is mainly conducted for scientific and research purposes and, therefore, an intense informative and training campaign should be undertaken in order to make this technique popular not only in the area of identification and assessment of environmental aspects but in other areas of its applications as well.

\section{REFERENCES}

[1] B. Poskrobko, "Environmental Management. Present and Future," Publishing House of CSDEM, Białystok, 2003.

[2] International Standard Organization ISO 14001, "Environmental Management Systems-Requirements with Guidance for Use," 2005.

[3] A. Matuszak-Flejszman, "Determinants of Improving the Environmental Management System According to Requirements of the Norm ISO 14001," Publishing House of Poznan University of Economics, Poznan, 2010.

[4] J. Kasprzak and P. Kurczewski, "Life Cycle Assessment-LCM," In: P. Kurczewski and A. Lewandowska, Eds., Principles of Eco-Designing the Technical Objects for the Purposes of Their Life Cycle Management, Publishing House KMB DRUK, Poznan, 2008.

[5] J. Brady, "Environmental Management in Organizations: The IEMA Handbook," Publishing House Earthscan, London, 2005.

[6] K. Donnelly, Z. Beckett-Furnell, S. Traeger, T. Okrasinski and S. Holman, "Eco-Design Implemented through a Product-Based Environmental Management System," Journal of Cleaner Production, Vol. 14, No. 15-16, 2006, pp. 1357-1367. doi:10.1016/j.jclepro.2005.11.029

[7] R. van Berkel, M. van Kampen and J. Kortman, “Oppor- 
tunities and Constraints for Product-Oriented Environmental Management Systems (P-EMS)," Journal of Cleaner Production, Vol. 7, No. 6, 1999, pp. 447-455. doi:10.1016/S0959-6526(99)00232-2

[8] F. de Bakker, O. Fisscher and A. Brack, "Organizing Product-Oriented Environmental Management from a Firm's Perspective," Journal of Cleaner Production, Vol. 10, No. 5, 2002, pp. 455-464. doi:10.1016/S0959-6526(02)00012-4

[9] H. Baumann and A. M. Tillman, "The Hitch Hiker's Guide to LCA: An Orientation in Life Cycle Assessment Methodology and Application," Studentlitteratur, Lund, 2004.

[10] A. Lewandowska, "Environmental Life Cycle Assessment as a Tool for Identification and Assessment of Environmental Aspects in Environmental Management Systems (EMS). Part 1 Methodology," The International Journal of Life Cycle Assessment, Vol. 16, No. 2, 2011, pp. 178-186. doi:10.1007/s11367-011-0253-2

[11] S. P. Lim and J. M. Park, "Environmental Indicators for Communication of Life Cycle Impact Assessment Results and Their Applications," Journal of Environmental Management, Vol. 90, No. 11, 2009, pp. 3305-3312. doi:10.1016/j.jenvman.2009.05.003

[12] M. Gernuks, J. Buchgeister and L. Schebek, "Assessment of Environmental Aspects and Determination of Environmental Targets within Environmental Management Systems (EMS) - Development of a Procedure for Volkswagen," Journal of Cleaner Production, Vol. 15, No. 1112, 2007, pp. 1063-1075. doi:10.1016/j.jclepro.2006.06.003

[13] K. Konieczy, "Possibility of Use LCA for Creation Environmental Management System in Enterprise," In: J. Kulczycka, Ed., Life Cycle Assessment LCA-A New Tool for Environmental Management, Publishing House of IGSMiE PAN, Cracow, 2011.

[14] R. S. Stowe, "Methodologies to Identify Environmental Aspects and Resulting Impacts," ISO Management Systems, 2001. www.iso.org/ims

[15] J. Łunarski, "Environmental Aspects," Publishing House of Rzeszow University of Technology, Rzeszow, 2006.

[16] B. Gajdzik and A. Wyciślik, "Selected Aspects of the Environmental Protection and the Environmental Management," Publishing House of Gliwice University of Technology, Gliwice, 2007.

[17] K. Liu, Ch. Fan, Ch.-Y. Ko and Ch.-W. Chen, "Combining Risk Assessment, Life Cycle Assessment and MultiCriteria Decision Analysis to Estimate Environmental Aspects in EMS," The International Journal of Life Cycle Assessment, Vol. 16 No. 3, 2012, pp. 247-257.

[18] T. Zobel, C. Almroth, J. Bresky and J. O. Burman, "Identification and Assessment of Environmental Aspects in
EMS Context: An Approach to a New Reproducible Method Based on LCA Methodology," Journal of Cleaner Production, Vol. 10, No. 4, 2002, pp. 381-396. doi:10.1016/S0959-6526(01)00054-3

[19] T. Zobel and J. O. Burman, "Factors of Importance in Identification and Assessment of Environmental Aspects in EMS Context: Experiences in Swedish Organizations," Journal of Cleaner Production, Vol. 12, No. 1, 2004, pp. 13-27. doi:10.1016/S0959-6526(02)00167-1

[20] K. Lundberg, B. Balfors and L. Folkeson, "Identification of Environmental Aspect in an EMS Context: A Methodological Framework for the Swedish National Rail Administration," Journal of Cleaner Production, Vol. 15, No. 5, 2007, pp. 385-394. doi:10.1016/j.jclepro.2005.11.017

[21] A. Lewandowska, A. Matuszak-Flejszman, K. Joachimiak and A. Ciroth, "Environmental Life Cycle Assessment as a Tool for Identification and Assessment of Environmental Aspects in Environmental Management Systems (EMS). Part 2-Case Studies," The International Journal of Life Cycle Assessment, Vol. 16 No. 3, 2011, pp. 247 257. doi:10.1007/s11367-011-0252-3

[22] A. Lewandowska, P. Kurczewski, J. Kulczycka, A. Matuszak-Flejszman, K. Joachimiak, H. Baumann and A. Ciroth, "LCA as an Element of Environmental Management Systems - Comparison of Conditions in Selected Organizations in Poland, Sweden and Germany. Part 1Background and Initial Assumptions," The International Journal of Life Cycle Assessment, Vol. 18, No. 2, 2013, pp. 472-480. doi:10.1007/s11367-012-0480-1

[23] A. Lewandowska, P. Kurczewski, J. Kulczycka, A. Matuszak-Flejszman, K. Joachimiak, H. Baumann and A. Ciroth, "LCA as an Element of Environmental Management Systems - Comparison of Conditions in Selected Organizations in Poland, Sweden and Germany. Part 2Results and Survey Research," The International Journal of Life Cycle Assessment, Vol. 18, No. 2, 2013b, pp. 481490. doi:10.1007/s11367-012-0481-0

[24] H. Baumann, "LCA Use in Swedish Industry," The International Journal of Life Cycle Assessment, Vol. 1 No. 3, 1996, pp. 122-126.

[25] P. Frankl, F. Rubik and M. Bartolomeo, "Life Cycle Assessment in Industry and Business: Adoption Patterns, Applications and Implications," Springer, Berlin, 2000.

[26] Z. Kowalski, J. Kulczycka and M. Góralczyk, "Ecological Evaluations of the Life Cycle of Manufacturing Processes," Publishing House of PWN, Warszawa, 2007

[27] "The Attitudes of European Citizens towards Environment," 2007.

http://ec.europa.eu/enviroment/archives/barometer/pdf/

[28] K. Joachimiak, "LCA in Environmental Management System," Eco-Manager, No. 6, 2011, pp. 37-38. 